\title{
3Es System Optimization under Uncertainty Using Hybrid Intelligent Algorithm: A Fuzzy Chance-Constrained Programming Model
}

\author{
Jiekun Song, Kaixin Zhang, and Zijian Cao \\ School of Economics and Management, China University of Petroleum, Qingdao 266580, China \\ Correspondence should be addressed to Jiekun Song; songjiekun@163.com
}

Received 11 May 2016; Revised 7 July 2016; Accepted 17 July 2016

Academic Editor: Dan Ralescu

Copyright (c) 2016 Jiekun Song et al. This is an open access article distributed under the Creative Commons Attribution License, which permits unrestricted use, distribution, and reproduction in any medium, provided the original work is properly cited.

\begin{abstract}
Harmonious development of 3Es (economy-energy-environment) system is the key to realize regional sustainable development. The structure and components of 3Es system are analyzed. Based on the analysis of causality diagram, GDP and industrial structure are selected as the target parameters of economy subsystem, energy consumption intensity is selected as the target parameter of energy subsystem, and the emissions of COD, ammonia nitrogen, $\mathrm{SO}_{2}$, and $\mathrm{NO}_{X}$ and $\mathrm{CO}_{2}$ emission intensity are selected as the target parameters of environment system. Fixed assets investment of three industries, total energy consumption, and investment in environmental pollution control are selected as the decision variables. By regarding the parameters of 3Es system optimization as fuzzy numbers, a fuzzy chance-constrained goal programming (FCCGP) model is constructed, and a hybrid intelligent algorithm including fuzzy simulation and genetic algorithm is proposed for solving it. The results of empirical analysis on Shandong province of China show that the FCCGP model can reflect the inherent relationship and evolution law of 3Es system and provide the effective decision-making support for 3Es system optimization.
\end{abstract}

\section{Introduction}

How to balance the economic development, energy security, and environmental protection to achieve sustainable development has been one of the greatest challenges of the 21st century. Referred to as the 3Es (economy-energyenvironment) issues, they often involve simultaneous consideration of the speed and quality of economic development, energy consumption, and pollutants and GHGs (greenhouse gases) emissions. Therefore, it is imperative to optimize 3Es system in order to achieve coordinated development. The coordination is not only the basic assurance for the energy security and sustainable development of economy, but also an effective way to reduce environmental pollution.

There are some researches on the optimization of 3Es system, and a number of optimization models have been proposed. According to the modelling method, 3Es models can be divided into three categories, that is, top-down model, bottom-up model, and mixed model [1]. CGE (computable general equilibrium) model is a representative top-down model, which takes economic model as the core technology, and focuses on the interactions between energy price, economic elasticity, energy consumption, and energy production [2-4]. MARKAL (market allocation model), EFOM (energy flow optimization model), and LEAP (long range energy alternatives planning model) are widely used bottom-up models, and they apply optimization and simulation to predict and optimize the elements of 3Es. The most representative mixed models are NEMS (national energy modelling systems) and IIASA-WEC 3Es (IIASA-WEC energyeconomic-environment model), and they optimize the whole 3 Es system through emulation and simulation. Because topdown models do not have to describe energy and environmental technologies in detail, many researchers constructed top-down models. Zhang and Li constructed TH3EM (Tsinghua hybrid energy-economy-environment assessment model) [5], which consist of CSCGEM, IESOM, and SICGE and other modules. Zhang et al. applied IESOM to simulate energy consumptions, energy structures, and carbon emissions in the different condition of emission mitigation 


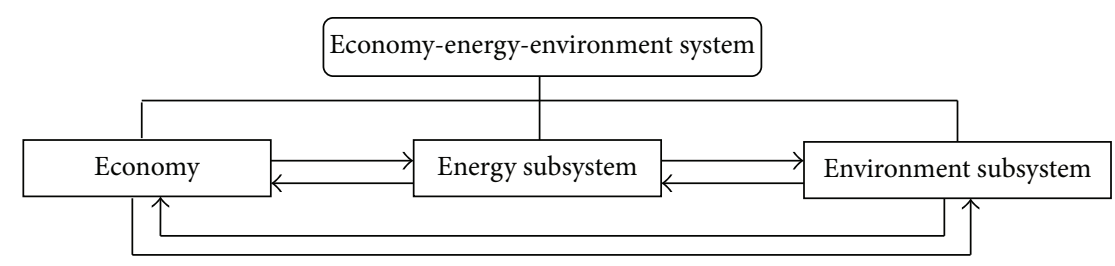

FIGURE 1: Elements and composition structure of 3Es system.

[6]. DeCarolis et al. applied ESOMs to uncover knife-edge solutions, explore alternative system configurations, and suggest different ways to achieve policy objectives under conditions of deep uncertainty [7]. Kambo et al. constructed a linear goal programming model for urban energy-economyenvironment interaction [8], which used energy demand, energy conservation, air pollution, economic cost of energy system, energy imports, and utilization capacity as objectives and constraints. Oliveira and Antunes constructed a multiple objective model of 3Es interactions based on the linear input-output structure of interindustry [9]. Wei et al. applied the historical statistical data of Beijing city to construct a multiobjective goal programming model for Beijing's coordinated development of population, resources, environment, and economy [10]. $\mathrm{Hu}$ et al. put forward an economy-energy-electricity-environment framework and summarized the energy usage management and integrated resource strategic planning of China [11]. The above models are all the deterministic programming models with real number coefficients. Actually, because of the uncertainty of system evolution and forecast, it is better to see the parameters of 3Es system model as uncertain parameters. Liu et al. constructed a chance-constrained mixed-integer linear programming model with hybrid interval parameters for nonrenewable energy resources management under uncertainty, with an objective of maximizing economic return under constraints of resources availability and environmental regulations [12]. Cai et al. developed an interactive decision support system based on an interval parameter linear programming model to aid decision makers in planning energy management systems [13]. Fragnière and Haurie constructed a MARKAL model of Geneva [14], which regarded different policy scenes as a random event with some kind of possibility distribution, and carried out energy planning by random decision tree technology. Lin and Huang developed an interval parameter two-stage stochastic municipal planning model for supporting decisions of energy systems planning and GHG emission management at a municipal level [15]. Borges and Antunes considered the right side of inputoutput model as triangular fuzzy numbers and constructed a fuzzy multiple objective decision support model for energyeconomy planning [16]. Weber and Martinsen constructed an energy system optimization model based on a fuzzy linear program and achieved an optimal compromise between system sustainability and cost minimization [17]. Zhang et al. adopted the fuzzy integral methods to offer an effective decision support for sustainable energy planning of Nanjing city [18].
In summary, 3Es system optimization is one of the significant ways to achieve the regional sustainable development. Extensive mathematical programming models have been put forward to demonstrate the relationships of 3Es system and obtain the optimal decision scheme. From the perspective of reality, uncertain models including interval, stochastic, and fuzzy programming models are better than deterministic models. Since plenty of statistical data is needed in the stochastic programming model to determine the probability distributions of variables, it is rarely used for 3Es optimization directly. Many interval and fuzzy programming models were constructed and applied for micro energy systems optimization, which were transformed into deterministic models with interaction parameters. Few studies constructed specifically the uncertain models of regional 3Es system considering targets of economy, energy, and environment subsystems simultaneously. In this paper, a fuzzy chance-constrained goal programming model (FCCGP) and its hybrid intelligent algorithm are put forward for optimization of 3Es system, and an empirical analysis on Shandong province is conducted for application of the above model and algorithm.

This paper is organized as follows: Section 2 analyzes the structure and components of 3Es system, selects the target parameters and decision variables, and constructs a FCCGP model for optimization of 3Es system. Section 3 provides a hybrid intelligent algorithm for solving the fuzzy model. Section 4 gives an empirical analysis on 3Es system optimization of Shandong province to testify the feasibility and validity of the FCCGP model and hybrid intelligent algorithm. Conclusions are presented in the last section.

\section{FCCGP Model for Optimization of 3Es System}

2.1. Economy-Energy-Environment System Analysis. 3Es system consists of three subsystems, namely, energy subsystem, economy subsystem, and environment subsystem, which interrelate with and influence each other. The development of each subsystem not only depends on its own structure but also depends on the other subsystems. The elements and composition structure of 3Es system are shown in Figure 1. Energy subsystem is the driving force of economy development and provides the power sources for the economic subsystem. Once the energy supply is threatened and unreliable, it will directly affect the economic output and even lead to economic recession. Meanwhile, economic subsystem plays important positive roles on the energy subsystem: firstly, economic development stimulates energy demand 


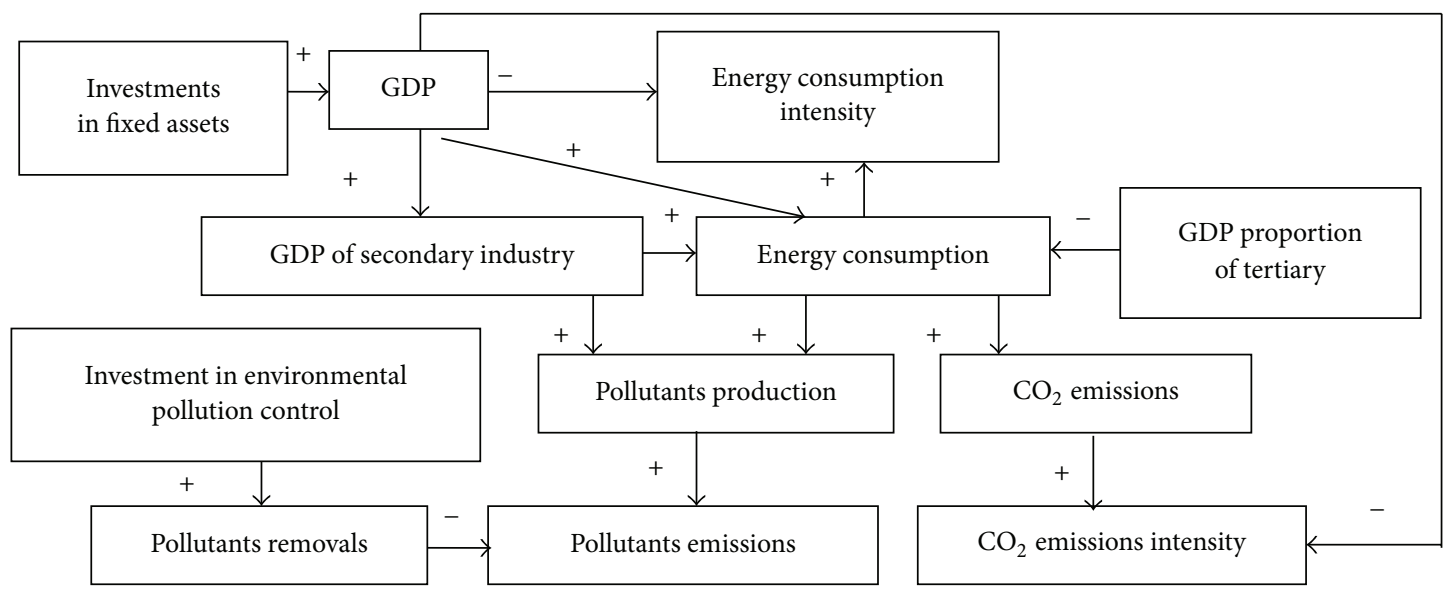

FIGURE 2: Causality diagram of 3Es system in Shandong province.

and provides the development space for energy subsystem; secondly, economic growth provides the material foundation of human, material, and financial resources for the development of energy subsystem; thirdly, economic growth drives the technological investment and progress in energy subsystem and consequently promotes the development of energy subsystem. Energy subsystem and environmental subsystem both conflict and coordinate with each other. The excessive exploitation and utilization of the energy subsystem can aggravate the environmental bearing capacity, and the degradation and destruction of the environment subsystem will make energy subsystem lose the foundation of exploitation. The development of economic subsystem, especially the industrial parts, accompanied by waste water, waste gas, solid waste, and GHGs, will cause environmental pollution, do harm to human health, and hinder the economic development.

Due to the fact that the impact value of energy investment and environmental pollution on the economic output is difficult to be estimated, the backward effects from energy of environment subsystem to economy subsystem are generally not considered into 3Es system optimization models. Referring to the literatures [8-10] and provincial development plan of China, the typical indicators are selected to construct the causality diagram shown in Figure 2. The main causal relationships are as follows:

(1) Investments in fixed assets $\rightarrow+$ GDP $\rightarrow+$ energy consumption $\rightarrow+\mathrm{CO}_{2}$ emissions $\rightarrow+\mathrm{CO}_{2}$ emissions intensity.

(2) GDP $\rightarrow+$ GDP of secondary industry $\rightarrow+$ pollutants production $\rightarrow+$ pollutants emissions.

(3) GDP proportion of tertiary $\rightarrow-$ energy consumption $\rightarrow+$ energy consumption intensity.

(4) Investment in environmental pollution control $\rightarrow+$ pollutants removals $\rightarrow-$ pollutants emissions.

2.2. Selection of Target Parameters and Decision Variables. Each subsystem of 3Es system has the corresponding targets.
Generally, economy subsystem pursues high GDP growth rate and scientific industrial structure. GDP and three industry structures are selected as the target parameters of economic subsystem:

$$
G_{t}=G_{0}(1+d)^{t}
$$

where $G_{0}$ and $G_{t}$ are the GDP of the basic year and the target year and $d$ is the average annual GDP growth rate.

Energy subsystem pursues lower growth rate of energy consumption and lower energy consumption intensity. Based on the target reduction ratio, the energy consumption intensity of the target year can be obtained by

$$
e_{t}=e_{0}(1-r) \text {, }
$$

where $e_{0}$ and $e_{t}$ are the energy consumption intensities of the basic year and the target year and $r$ is the reduction ratio of energy consumption intensity.

Environment subsystem pursues fewer emissions of pollutants and GHGs. The pollutants and GHGs usually include chemical oxygen demand (COD), ammonia nitrogen, sulphur dioxide $\left(\mathrm{SO}_{2}\right)$, nitrogen oxides $\left(\mathrm{NO}_{X}\right)$, and carbon dioxide $\left(\mathrm{CO}_{2}\right)$. Based on the reduction ratios, they can be computed by the following formula:

$$
\begin{gathered}
D_{t}=D_{0}\left(1-r_{D}\right), \\
A_{t}=A_{0}\left(1-r_{A}\right), \\
S_{t}=S_{0}\left(1-r_{S}\right), \\
N_{t}=N_{0}\left(1-r_{N}\right), \\
C_{t}=C_{0}\left(1-r_{C}\right),
\end{gathered}
$$

where $D_{0}, A_{0}, S_{0}$, and $N_{0}$ are the emissions of COD, ammonia nitrogen, $\mathrm{SO}_{2}$, and $\mathrm{NO}_{X}$ of the basic year, $D_{t}, A_{t}, S_{t}$, and $N_{t}$ are the emissions of the target year, $C_{0}$ and $C_{t}$ are carbon emission intensities of the basic year and the target year, and $r_{D}, r_{A}, r_{S}, r_{N}$, and $r_{C}$ are the reduction ratios of the above pollutants and $\mathrm{CO}_{2}$. 
According to the principles of controllability and exogenesis, the decision variables of the $3 \mathrm{Es}$ system include the investments in fixed assets of the three industries, total energy consumption, and total investment in environmental pollution control.

2.3. Formulation of FCCGP Model. 3Es system is a complex system and contains multiple optimization objectives. Generally, the target of economy subsystem includes two aspects: GDP of the target year is not lower than the planning value; industrial structure achieves the planning target; that is, the GDP proportions of primary industry and secondary industry are not higher than their target values and that of tertiary industry is not lower than its target value. The target of energy subsystem is that the energy consumption intensity is not higher than the planning value. The target of environment subsystem includes two aspects: the emissions of pollutants including $\mathrm{COD}$, ammonia nitrogen, $\mathrm{SO}_{2}$, and $\mathrm{NO}_{X}$ are not higher than their planning values; $\mathrm{CO}_{2}$ emissions intensity is not higher than its planning value.

Due to the small sample of historical data and the uncertainty of forecasting, many parameters of 3Es system can be seen as fuzzy parameters. In this paper, a fuzzy chance-constrained goal programming model (FCCGP) is constructed for optimizing 3Es system. According to the above targets of 3Es system, the constraints consist of two types: (a) the uncertain constraint that each subsystem achieves its targets holding with a certain confidence level; (b) technical constraints. The uncertain constraints are as follows.

(1) GDP of the target year equals the sum of the added values of three industries:

$$
G=\sum_{i=1}^{3}\left(I_{i} \times x_{i}\right),
$$

where $G$ is GDP of the target year, $x_{i}$ is the fixed assets investment in the $i$ th industry, $I_{i}$ is the added value of unit investment in the $i$ th industry, and $I_{i}$ are fuzzy variables, $i=1,2,3$.

(2) The fuzzy chance constraints that three industry structures of the target year should achieve the desired structure are satisfied with certain confidence levels:

$$
\begin{aligned}
& \operatorname{Cr}\left\{\frac{I_{1} \times x_{1}}{G}-g_{1} \leq d_{1}^{+}\right\} \geq \alpha_{1}, \\
& \operatorname{Cr}\left\{\frac{I_{2} \times x_{2}}{G}-g_{2} \leq d_{2}^{+}\right\} \geq \alpha_{2}, \\
& \operatorname{Cr}\left\{g_{3}-\frac{I_{3} \times x_{3}}{G} \leq d_{3}^{-}\right\} \geq \alpha_{3},
\end{aligned}
$$

where $\operatorname{Cr}\{A\}$ express the credibility that fuzzy event $A$ occurs, $g_{i}$ is the target value of GDP proportion of the $i$ th industry, and $\alpha_{i}$ are the predetermined confidence levels by the decision-maker, $i=1,2,3$.
(3) The constraint that GDP of the target year is not lower than the planning value is satisfied with a certain confidence level:

$$
\operatorname{Cr}\left\{G_{t}-G \leq d_{4}^{-}\right\} \geq \alpha_{4},
$$

where $G_{t}$ is the target value of GDP and $\alpha_{4}$ is the predetermined confidence level.

(4) The constraint that energy consumption intensity of the target year is not higher than the planning value is satisfied with a certain confidence level:

$$
\operatorname{Cr}\left\{\frac{x_{4}}{G}-e \leq d_{5}^{+}\right\} \geq \beta,
$$

where $x_{4}$ is total energy consumption, $e$ is the target value of energy consumption intensity, and $\beta$ is the predetermined confidence level.

(5) The constraints that the emissions of COD, ammonia nitrogen, $\mathrm{SO}_{2}, \mathrm{NO}_{X}$, and $\mathrm{CO}_{2}$ are not higher than their planning values are satisfied with certain confidence levels:

$$
\begin{array}{r}
\operatorname{Cr}\left\{P_{1} \times I_{2} \times x_{2}-E_{1} \times x_{5}-D \leq d_{6}^{+}\right\} \geq \gamma_{1}, \\
\operatorname{Cr}\left\{P_{2} \times I_{2} \times x_{2}-E_{2} \times x_{5}-A \leq d_{7}^{+}\right\} \geq \gamma_{2}, \\
\operatorname{Cr}\left\{P_{3} \times I_{2} \times x_{2}-E_{3} \times x_{5}-S \leq d_{8}^{+}\right\} \geq \gamma_{3}, \\
\operatorname{Cr}\left\{P_{4} \times I_{2} \times x_{2}-E_{4} \times x_{5}-N \leq d_{9}^{+}\right\} \geq \gamma_{4}, \\
\operatorname{Cr}\left\{\frac{c \times x_{4}}{G}-C \leq d_{10}^{+}\right\} \geq \gamma_{5},
\end{array}
$$

where $x_{5}$ is total investment in environmental pollution control, $P_{i}$ are the production coefficients of COD, ammonia nitrogen, $\mathrm{SO}_{2}$, and $\mathrm{NO}_{X}$, that is, the productions of COD, ammonia nitrogen, $\mathrm{SO}_{2}$, and $\mathrm{NO}_{X}$ per unit of the added value of secondary industry, $i=1,2,3,4$, respectively, $E_{i}$ are the removal coefficients of COD, ammonia nitrogen, $\mathrm{SO}_{2}$, and $\mathrm{NO}_{X}$, that is, the removals of COD, ammonia nitrogen, $\mathrm{SO}_{2}$, and $\mathrm{NO}_{X}$ per unit of investment in environmental pollution control, $i=1,2,3,4$, respectively, $c$ is $\mathrm{CO}_{2}$ emission coefficient, that is, $\mathrm{CO}_{2}$ emissions per unit of energy consumption, $D, A, S$, and $N$ are the target emissions of $\mathrm{COD}$, ammonia nitrogen, $\mathrm{SO}_{2}$, and $\mathrm{NO}_{X}, C$ is the target $\mathrm{CO}_{2}$ emission intensity, $P_{i}, E_{i}$, and $c$ are fuzzy variables, $i=$ $1,2,3,4$, and $\gamma_{1}, \gamma_{2}, \ldots, \gamma_{5}$ are the predetermined confidence levels by the decision-maker.

The technical constraints include the following.

(1) Each decision variable should be within a certain range:

$$
x_{i}^{-} \leq x_{i} \leq x_{i}^{+}, \quad i=1,2, \ldots, 5,
$$

where $x_{i}^{-}$and $x_{i}^{+}$are the lower limit and upper limit of the $i$ th decision variable.

(2) The sum of investments in fixed assets of three industries should be within a certain range:

$$
I^{-} \leq \sum_{i=1}^{3} x_{i} \leq I^{+},
$$


where $I^{-}$and $I^{+}$are the lower limit and upper limit of the fixed assets investment of three industries.

(3) All the deviation variables are nonnegative:

$$
d_{1}^{+}, d_{2}^{+}, d_{3}^{-}, d_{4}^{-}, d_{5}^{+}, d_{6}^{+}, d_{7}^{+}, d_{8}^{+}, d_{9}^{+}, d_{10}^{+} \geq 0
$$

The objective of the model is to minimize the total deviations according to the priority structure and target levels set by the decision-maker:

$$
\begin{gathered}
\min \left\{P_{i_{1}}\left(w_{1} d_{1}^{+}+w_{2} d_{2}^{+}+w_{3} d_{3}^{-}+w_{4} d_{4}^{-}\right), P_{i_{2}} d_{5}^{+},\right. \\
\left.P_{i_{3}}\left(u_{1} d_{6}^{+}+u_{2} d_{7}^{+}+u_{3} d_{8}^{+}+u_{4} d_{9}^{+}+u_{5} d_{10}^{+}\right)\right\},
\end{gathered}
$$

where $P_{i_{1}}, P_{i_{2}}, P_{i_{3}}$ are the preemptive priority factors which express the relative importance of economy, energy, and environment targets, respectively. For example, if the priority order of them is economy $>$ energy $>$ environment, then $i_{1}=1, i_{2}=2, i_{3}=3$, and $P_{1} \gg P_{2} \gg P_{3} \cdot w_{i}$ and $u_{k}$ are the weighting factors corresponding to the deviations of economy subsystem and environment subsystem, $i=$ $1,2,3,4, k=1,2, \ldots, 5$, respectively, and they are all positive.

\section{Solution Method of FCCGP Model}

3.1. Fuzzy Simulation. Fuzzy simulation is a technology of sampling test for the fuzzy system model. If $\xi=$ $f\left(\xi_{1}, \xi_{2}, \ldots, \xi_{n}\right)$ is a fuzzy vector defined on the credibility space $(\Theta, P(\Theta), C r), \alpha$ is predetermined confidence level, and the algorithm of fuzzy simulation for $\max \{\bar{f} \mid \operatorname{Cr}\{f(\mathbf{x}, \boldsymbol{\xi}) \geq$ $\bar{f}\} \geq \alpha\}$ is as follows [19].

Step 1. Generate $\theta_{k}$ from $\Theta$ such that $\operatorname{Cr}\left\{\theta_{k}\right\} \geq \varepsilon / 2(k=$ $1,2, \ldots, N)$, where $\varepsilon$ is a sufficiently small number.

Step 2. Find the maximal value $r$ such that $L(r) \geq \alpha$ by employing bisection search method, where

$$
\begin{aligned}
L(r) & =\frac{1}{2}\left(\max _{1 \leq k \leq N}\left\{v_{k} \mid f\left(\mathbf{x}, \boldsymbol{\xi}\left(\theta_{k}\right)\right) \geq r\right\}\right. \\
+ & \left.\min _{1 \leq k \leq N}\left\{1-v_{k} \mid f\left(\mathbf{x}, \boldsymbol{\xi}\left(\theta_{k}\right)\right)<r\right\}\right) .
\end{aligned}
$$

Step 3. Return $r$ as the estimation of $\bar{f}$.

3.2. Hybrid Intelligent Algorithm. A hybrid intelligent algorithm can be employed for solving the fuzzy chanceconstrained goal programming model, which integrates fuzzy simulation and genetic algorithm. The procedure of this algorithm is as follows [20].

Step 1. Initialize a population with $m$ chromosomes randomly, and the $r$ th chromosome $\mathbf{x}^{r}=\left(x_{1}^{r}, x_{2}^{r}, \ldots, x_{5}^{r}\right)$ satisfies the constraints as follows:

$$
\begin{aligned}
& x_{i}^{-} \leq x_{i}^{r} \leq x_{i}^{+}, \quad i=1,2, \ldots, 5 ; r=1,2, \ldots, m, \\
& I^{-} \leq \sum_{i=1}^{3} x_{i}^{r} \leq I^{+} .
\end{aligned}
$$

Step 2. According to the credibility distributions of all the fuzzy variables including $I_{i}, P_{j}, E_{j}$, and $c, i=1,2,3, j=$ $1,2,3,4$, fuzzy simulation is applied to generate the data of uncertain functions $\left(e_{1}, e_{2}, \ldots, e_{10}\right)$ like

$$
\begin{aligned}
e_{1} & =\max \left\{r_{1} \mid \operatorname{Cr}\left\{\frac{I_{1} \times x_{1}}{G} \leq r_{1}\right\} \geq \alpha_{1}\right\}, \\
e_{2} & =\max \left\{r_{2} \mid \operatorname{Cr}\left\{\frac{I_{2} \times x_{2}}{G} \leq r_{2}\right\} \geq \alpha_{2}\right\}, \\
e_{3} & =\max \left\{r_{3} \mid \operatorname{Cr}\left\{\frac{I_{3} \times x_{3}}{G} \geq r_{3}\right\} \geq \alpha_{3}\right\}, \\
e_{4} & =\max \left\{\operatorname{Cr}\left\{r_{4} \mid G \geq r_{4}\right\} \geq \alpha_{4}\right\}, \\
e_{5} & =\max \left\{r_{5} \mid \operatorname{Cr}\left\{\frac{x_{4}}{G} \leq r_{5}\right\} \geq \beta\right\}, \\
e_{6} & =\max \left\{r_{6} \mid \operatorname{Cr}\left\{P_{1} \times I_{2} \times x_{2}-E_{1} \times x_{5} \leq r_{6}\right\} \geq \gamma_{1}\right\}, \\
e_{7} & =\max \left\{r_{7} \mid \operatorname{Cr}\left\{P_{2} \times I_{2} \times x_{2}-E_{2} \times x_{5} \leq r_{7}\right\} \geq \gamma_{2}\right\}, \\
& =\max \left\{r_{9} \mid \operatorname{Cr}\left\{P_{4} \times I_{2} \times x_{2}-E_{4} \times x_{5} \leq r_{9}\right\} \geq \gamma_{4}\right\}, \\
e_{10} & =\max \left\{r_{10} \mid \operatorname{Cr}\left\{\frac{c \times x_{4}}{G} \leq r_{10}\right\} \geq \gamma_{5}\right\} . \\
e_{8} & =\max \left\{r_{8} \mid \operatorname{Cr}\left\{P_{3} \times I_{2} \times x_{2}-E_{3} \times x_{5} \leq r_{8}\right\} \geq \gamma_{3}\right\},
\end{aligned}
$$

Step 3. Calculate the values of deviation variables of each chromosome: $d_{1}^{+}=\left[e_{1}-g_{1}\right] \vee 0, d_{2}^{+}=\left[e_{2}-g_{2}\right] \vee 0$, $d_{3}^{-}=\left[g_{3}-e_{3}\right] \vee 0, d_{4}^{-}=\left[G_{t}-e_{4}\right] \vee 0, d_{5}^{+}=\left[e_{5}-e\right] \vee 0$, $d_{6}^{+}=\left[e_{6}-D\right] \vee 0, d_{7}^{+}=\left[e_{7}-A\right] \vee 0, d_{8}^{+}=\left[e_{8}-S\right] \vee 0$, $d_{9}^{+}=\left[e_{9}-N\right] \vee 0$, and $d_{10}^{+}=\left[e_{10}-C\right] \vee 0$, and calculate their weighted sum

$$
\begin{aligned}
& P_{i_{1}}\left(w_{1} d_{1}^{+}+w_{2} d_{2}^{+}+w_{3} d_{3}^{-}+w_{4} d_{4}^{-}\right)+P_{i_{2}} d_{5}^{+} \\
& \quad+P_{i_{3}}\left(u_{1} d_{6}^{+}+u_{2} d_{7}^{+}+u_{3} d_{8}^{+}+u_{4} d_{9}^{+}+u_{5} d_{10}^{+}\right)
\end{aligned}
$$

as the objective value.

Step 4. Compare all the objective values of $m$ chromosomes, and rearrange them in descending order. Calculate the cumulative possibility of the sorted chromosome:

$$
p_{r}=\sum_{t=1}^{r} a(1-a)^{t-1}, \quad r=1,2, \ldots, m,
$$

where $a$ is the evaluation function parameter, $0<a<1$.

Step 5. Select chromosomes by spinning the roulette wheel; that is, repeat the following process $m$ times: generating a random number $p$ in $\left(0, p_{m}\right)$, the $r$ th chromosome is selected if $p_{r-1}<p \leq p_{r}$. Output the new population $\mathbf{x}^{f}=\left(x_{1}^{f}, x_{2}^{f}\right.$, $\left.\ldots, x_{5}^{f}\right), f=1,2, \ldots, m$. 
TABLE 1: Data of the fixed assets investments, energy consumptions, and investment in environmental pollution control of Shandong province from 2000 to 2014 .

\begin{tabular}{|c|c|c|c|c|c|}
\hline \multirow{2}{*}{ Year } & \multicolumn{3}{|c|}{ Fixed assets investment $\left(10^{8}\right.$ Yuan $)$} & \multirow{2}{*}{$\begin{array}{c}\text { Total energy } \\
\text { consumption }\left(10^{4} \text { tce }\right)\end{array}$} & \multirow{2}{*}{$\begin{array}{l}\text { Investment in environmental pollution } \\
\text { control }\left(10^{8} \text { Yuan }\right)\end{array}$} \\
\hline & Primary industry & Secondary industry & Tertiary industry & & \\
\hline 2000 & 77.1 & 1176.7 & 1288.8 & 11361.9 & 76.2 \\
\hline 2001 & 78.2 & 1193.1 & 1306.9 & 9955.0 & 89.8 \\
\hline 2002 & 79.1 & 1206.3 & 1321.3 & 14599.0 & 144.6 \\
\hline 2003 & 81.4 & 1241.2 & 1359.6 & 16624.8 & 156.4 \\
\hline 2004 & 87.4 & 1333.1 & 1460.2 & 19623.7 & 191.9 \\
\hline 2005 & 89.9 & 1371.1 & 1501.8 & 24162.0 & 238.8 \\
\hline 2006 & 91.5 & 1395.8 & 1528.8 & 26759.3 & 258.1 \\
\hline 2007 & 95.2 & 1452.2 & 1590.6 & 29176.6 & 320.8 \\
\hline 2008 & 102.5 & 1564.0 & 1713.1 & 30570.0 & 432.2 \\
\hline 2009 & 99.4 & 1515.5 & 1660.0 & 32420.2 & 459.5 \\
\hline 2010 & 103.0 & 1570.7 & 1720.4 & 34807.8 & 483.9 \\
\hline 2011 & 110.0 & 1678.1 & 1838.1 & 37132.0 & 614.1 \\
\hline 2012 & 110.9 & 1692.2 & 1853.5 & 38899.3 & 739.1 \\
\hline 2013 & 111.4 & 1698.8 & 1860.7 & 35358.0 & 848.0 \\
\hline 2014 & 111.7 & 1703.9 & 1866.3 & 36511.0 & 823.8 \\
\hline
\end{tabular}

Sources: Shandong Statistics Yearbook 2001-2015 and China Energy Statistical Yearbook 2001-2015.

Note: - indicates the lack of data.

Step 6. Set a parameter $p_{j}$ as the probability of crossover, and repeat the following process from $f=1$ to $m$ : generating a random number $q$ from the interval $[0,1]$, the chromosome $\mathbf{x}^{f}$ is selected as a parent if $q<p_{j}$. Make the linear crossover operation on the parent, and output the new population $\mathbf{x}^{c}=$ $\left(x_{1}^{c}, x_{2}^{c}, \ldots, x_{3}^{c}\right), c=1,2, \ldots, m$.

Step 7. Set a parameter $p_{b}$ as the probability of mutation, and repeat the following process from $c=1$ to $m$ : generating a random number $s$ from the interval $[0,1]$, the chromosome $\mathbf{x}^{c}$ is selected as a parent if $s<p_{b}$. Make mutation operation on the parent, and output the new population $\mathbf{x}^{b}=$ $\left(x_{1}^{b}, x_{2}^{b}, \ldots, x_{5}^{b}\right), b=1,2, \ldots, m$, where all the chromosomes satisfy the constraints.

Step 8. Repeat the second to seventh steps for $T$ cycles, and output the best chromosome as the optimal solution.

\section{Empirical Analysis on Shandong Province}

4.1. Data of Parameters. As a major economic province of China, Shandong province has achieved significant economic growth, and since 2007, its economic output has been ranked third in 31 provinces. Although many efforts have been made for energy saving and pollutants reduction, the energy efficiency level of Shandong province still falls behind the national average level [21, 22], and the major pollutants' emissions are still the largest. In this paper, empirical analysis is conducted on Shandong province, which provides the modelling process of the above FCCGP model and effective decision-making supports for its 3Es system optimization.
The data of the fixed assets investments of three industries at 2000 price index, total energy consumptions, and investment in environmental pollution control from 2000 to 2014 are shown in Table 1. All the indicators show the upward trend; therefore, regression, grey forecasting, and other forecasting methods can be used to forecast the future values theoretically.

The forecast of the fixed assets investment in primary industry is taken as an example to illustrate the application of various methods. Using the annual sequence number as independent variable, the linear regression (LR) equation of the fixed assets investment in primary industry can be obtained as follows:

$$
F I_{1}=2.8271 t+72.6295
$$

$(60.7818)(21.5116)$

$$
R^{2}=0.9727, F=426.7498, \text { sig. }=1.51 \mathrm{e}-11 .
$$

Note: data in the parentheses denote $t$-test values.

$t$-test and $F$ value show that the regression equation is significant and can be used for short-term forecasting. Inputting $t=16$ into the equation, the fixed assets investment in primary industry in 2015 is 117.9 billion Yuan.

By first-order accumulating operation on the raw data, the accumulated values of the fixed assets investment in primary industry can be represented as a row vector $X^{(1)}=$ $\{77.1,155.3, \ldots, 1428.7\}$, which satisfies the grey exponential law basically. According to grey forecasting (GF) theory, the albino equation can be written as follows:

$$
\frac{d x^{(1)}}{d_{t}}+a x^{(1)}=b,
$$


TABLE 2: Forecast results of decision variables in 2015.

\begin{tabular}{lccccc}
\hline $\begin{array}{l}\text { Forecast } \\
\text { method }\end{array}$ & \multicolumn{3}{c}{ Fixed assets investment $\left(10^{8}\right.$ Yuan $)$} & $\begin{array}{c}\text { Total energy } \\
\text { Primary industry }\end{array}$ & $\begin{array}{c}\text { Investment in environmental pollution } \\
\text { Secondary industry }\end{array}$ \\
\hline LR & 117.9 & 1797.7 & 1969.1 & 43613.5 & 851.2 \\
GF & 119.6 & 1824.8 & 1998.7 & 45597.1 & 1112.7 \\
ER & 120.2 & 1833.1 & 2008.0 & 51777.5 & 1211.8 \\
PR & 109.6 & 1672.5 & 1831.9 & 40551.8 & 735.2 \\
QR & 130.7 & 1778.8 & 1948.3 & 38334.4 & 984.6 \\
CR & 111.9 & 1707.3 & 1870.3 & 33948.2 & 970.3 \\
Lower bound & 109.6 & 1672.5 & 1831.9 & 33948.2 & 735.2 \\
Upper bound & 130.7 & 1833.1 & 2008.0 & 51777.5 & 1211.8 \\
\hline
\end{tabular}

where $a$ and $b$ can be derived by using least squares estimation, and the calculation formulas are as follows:

$$
\begin{aligned}
{\left[\begin{array}{l}
a \\
b
\end{array}\right] } & =\left(B^{T} B\right)^{-1} B^{T} y_{n}, \\
B & =\left[\begin{array}{cc}
-\frac{1}{2}\left(x_{1}^{(1)}+x_{2}^{(1)}\right) & 1 \\
-\frac{1}{2}\left(x_{2}^{(1)}+x_{3}^{(1)}\right) & 1 \\
\vdots & \vdots \\
-\frac{1}{2}\left(x_{n-1}^{(1)}+x_{n}^{(1)}\right) & 1
\end{array}\right], \\
y_{n} & =\left[\begin{array}{c}
x_{2}^{(0)} \\
x_{3}^{(0)} \\
\vdots \\
x_{n}^{(0)}
\end{array}\right] .
\end{aligned}
$$

The results of $a$ and $b$ are -0.0295 and 75.6988 , and the grey forecast model is

$$
\begin{aligned}
\hat{x}_{t+1}^{(1)} & =\left(x_{1}^{(0)}-\frac{b}{a}\right) e^{-a t}+\frac{b}{a} \\
& =2641.9629 e^{0.0295 t}+75.6988 .
\end{aligned}
$$

Because the above formula is the accumulated forecast model, regressive operation should be implemented for restoring the original value. Grey forecast results and actual values of the fixed assets investment in primary industry from 2000 to 2014 are shown in Figure 3.

The results of residual test and posterior variance test are as follows. The maximum relative error is $5.10 \%$, the average relative error is $1.89 \%$, the forecast accuracy is $98.11 \%$, the posterior error ratio is 0.1945 , and the small error frequency is 1 . The test results show that grey forecast model has high precision and can be used for short-term forecasting. Inputting $t=16$ into the model, the fixed assets investment of the first industry in 2015 is 119.6 billion Yuan.

In addition to the above forecasting methods, exponential regression (ER), power function regression (PR), quadratic

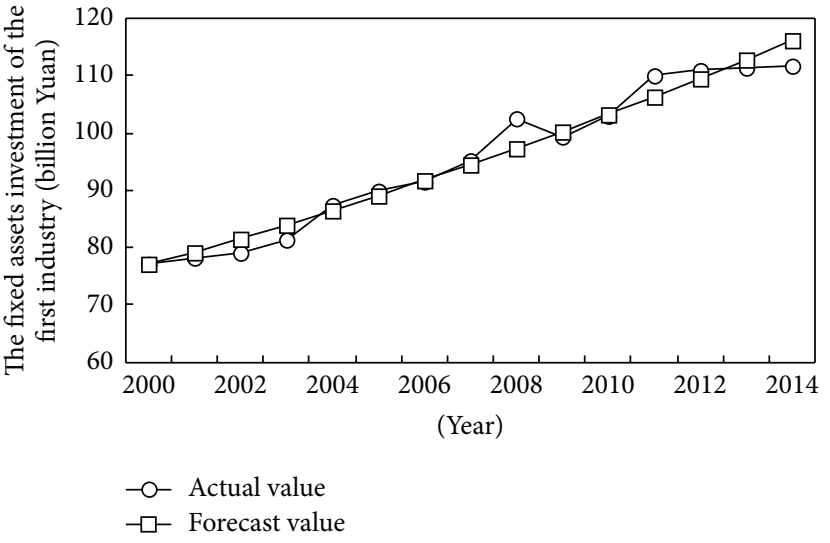

FIGURE 3: Comparison of grey forecast results and actual values.

regression $(\mathrm{QR})$, and cubic curve regression $(\mathrm{CR})$ can also be applied to fit the relation between the fixed assets investment in primary industry and the annual sequence number. The regression results are obtained as follows:

$$
\begin{aligned}
& \text { ER: } F I_{1}=74.245 e^{0.0301 t}, \quad R^{2}=0.9691, \\
& \text { PR: } F I_{1}=69.661 t^{0.1636}, \quad R^{2}=0.8773, \\
& \text { QR: } F I_{1}=0.0274 t^{2}+3.2653 t+71.391, \\
& \qquad R^{2}=0.9736, \\
& \text { CR: } F I_{1}=-0.0191 t^{3}+0.4308 t^{2}+0.2372 t+76.065, \\
& \qquad R^{2}=0.9827 .
\end{aligned}
$$

All the correlation coefficient square values are greater than 0.8 , so the above regression equations are significant. Inputting $t=16$ into them, the forecast results are 120.2, 109.6, 130.7, and 111.9, respectively. Then the maximum and minimum values of the above results can be taken as the lower and upper bounds of the variable $x_{1}$ in 2015. In the same way, the forecast results of the other four decision variables in 2015 and their lower and upper bounds can be obtained as shown in Table 2.

The added values per unit investment of three industries from 2000 to 2014 are shown in Figure 4, and all three curves 
TABLE 3: Forecast results of the added values per unit investment of three industries in 2015 (unit: Yuan/Yuan).

\begin{tabular}{lccc}
\hline Forecast method & & The added values per unit investment \\
Secondary industry & 14.77 & Tertiary industry \\
\hline LR & 20.57 & 16.68 & 7.48 \\
GF & 20.64 & 17.31 & 8.31 \\
ER & 20.66 & 12.72 & 8.37 \\
PR & 19.74 & 15.83 & 6.38 \\
QR & 20.80 & 15.62 & 8.14 \\
CR & 21.21 & 8.01 \\
\hline
\end{tabular}

TABLE 4: The production coefficients of pollutants and $\mathrm{CO}_{2}$ emission coefficients from 2000 to 2014 .

\begin{tabular}{|c|c|c|c|c|c|}
\hline \multirow{2}{*}{ Year } & \multicolumn{4}{|c|}{ The production coefficients of pollutants ( $\mathrm{t} / 10^{8}$ Yuan) } & \multirow{2}{*}{$\begin{array}{c}\mathrm{CO}_{2} \text { emission coefficients } \\
\left(\mathrm{t} / 10^{4} \text { Yuan }\right)\end{array}$} \\
\hline & $\mathrm{COD}$ & Ammonia nitrogen & $\mathrm{SO}_{2}$ & $\mathrm{NO}_{X}$ & \\
\hline 2000 & 531.08 & - & 427.73 & - & 1.5588 \\
\hline 2001 & 473.72 & 13.63 & 383.51 & - & 1.5956 \\
\hline 2002 & 385.00 & 12.52 & 340.54 & - & 1.2807 \\
\hline 2003 & 338.53 & 10.41 & 339.03 & - & 1.5982 \\
\hline 2004 & 280.36 & 9.58 & 293.57 & - & 1.6750 \\
\hline 2005 & 247.16 & 9.03 & 284.08 & - & 2.2665 \\
\hline 2006 & 199.37 & 13.91 & 311.22 & 121.74 & 2.0849 \\
\hline 2007 & 180.69 & 7.29 & 251.87 & 89.25 & 1.9663 \\
\hline 2008 & 182.83 & 8.00 & 280.38 & 77.03 & 1.9407 \\
\hline 2009 & 165.39 & 9.27 & 273.67 & 73.96 & 1.7856 \\
\hline 2010 & 154.63 & 11.32 & 268.44 & 69.16 & 1.6662 \\
\hline 2011 & 150.94 & 7.00 & 314.13 & 68.12 & 1.5793 \\
\hline 2012 & 134.31 & 5.69 & 239.98 & 62.21 & 1.5230 \\
\hline 2013 & 98.60 & 4.26 & 247.97 & 59.57 & 1.2420 \\
\hline 2014 & 86.96 & 3.42 & 268.11 & 61.15 & 1.2194 \\
\hline
\end{tabular}

Note: - indicates the lack of data.

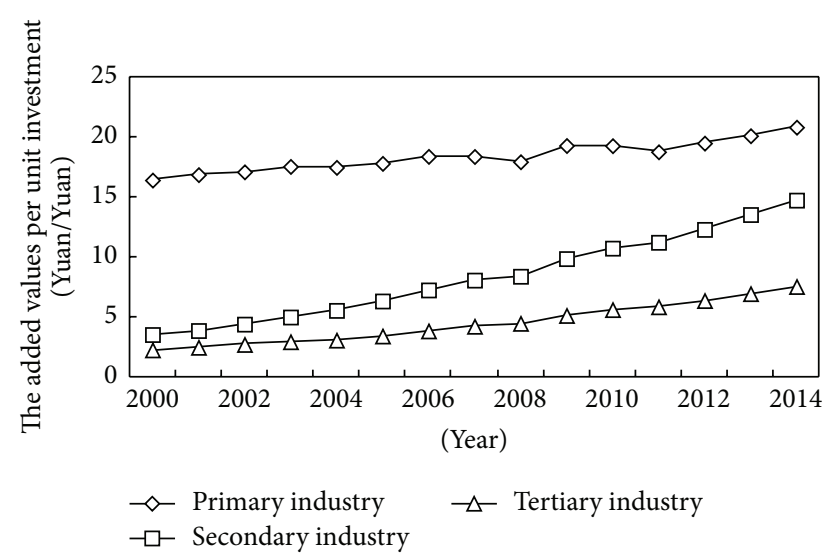

FIGURE 4: The added values per unit investment of three industries from 2000 to 2014 .

show rising trends. By using regression and grey forecast methods, the forecast values in 2015 are shown in Table 3.

The production coefficients of four pollutants and $\mathrm{CO}_{2}$ emission coefficients from 2000 to 2014 are shown in Table 4.
The forecast values of them by different methods in 2015 are shown in Table 5, where, due to the forecast significance, $\mathrm{CO}_{2}$ emission coefficients are forecasted based on the samples of 2005-2014.

The removal coefficients of COD, ammonia nitrogen, $\mathrm{SO}_{2}$, and $\mathrm{NO}_{X}$ from 2000 to 2014 are shown in Table 6, and the forecast values of them in 2015 are shown in Table 7.

All the forecast methods are applied according to their premises, so the above results are reasonable theoretically. Due to less effective forecast results, the above indicators can be seen as interval or fuzzy variables. In order to make full use of the forecast results, all the indicators are considered to obey the triangular fuzzy distributions. The triangular fuzzy variable $T\left(u_{1}, u_{2}\right.$, and $\left.u_{3}\right)$ is fully determined by the triplet $\left(u_{1}, u_{2}\right.$, and $\left.u_{3}\right)$ of crisp numbers with $u_{1}<u_{2}<u_{3}$, whose membership function is given by

$$
\mu(x)= \begin{cases}\frac{x-u_{1}}{u_{2}-u_{1}}, & \text { if } u_{1} \leq x \leq u_{2}, \\ \frac{x-u_{3}}{u_{2}-u_{3}}, & \text { if } u_{2} \leq x \leq u_{3}, \\ 0, & \text { otherwise, }\end{cases}
$$


TABLE 5: Forecast results of the production coefficients of four pollutants and $\mathrm{CO}_{2}$ emissions coefficients in 2015.

\begin{tabular}{lccccc}
\hline \multirow{2}{*}{ Forecast method } & \multicolumn{4}{c}{ The production coefficients of pollutants $\left(\mathrm{t} / 10^{8}\right.$ Yuan) } & $\mathrm{NO}_{X}$ \\
& $\mathrm{COD}$ & Ammonia nitrogen & $\mathrm{SO}_{2}$ & emissions coefficient $(\mathrm{t} / \mathrm{t})$ \\
\hline LR & $14.33^{*}$ & 4.24 & 225.62 & 45.22 & 1.1026 \\
GF & 74.65 & 5.32 & 237.77 & 53.96 & 1.1842 \\
ER & 80.78 & 4.51 & 234.10 & 50.72 & 1.1640 \\
PR & 114.70 & 5.84 & 250.08 & 56.27 & 1.3464 \\
QR & 127.19 & 2.91 & 282.99 & 70.03 & 1.0765 \\
CR & 57.94 & $-0.27^{*}$ & 239.55 & 48.1 & 0.9863 \\
\hline
\end{tabular}

Note: $*$ indicates that the value does not conform to the reality and should be discarded.

TABLE 6: The removal coefficients of four pollutants from 2000 to 2014 (unit: t/10 ${ }^{8}$ Yuan).

\begin{tabular}{|c|c|c|c|c|}
\hline \multirow{2}{*}{ Year } & \multicolumn{4}{|c|}{ The removal coefficients of pollutants } \\
\hline & COD & Ammonia nitrogen & $\mathrm{SO}_{2}$ & $\mathrm{NO}_{X}$ \\
\hline 2000 & 22312.87 & - & 4204.09 & - \\
\hline 2001 & 19102.87 & 386.51 & 4054.03 & - \\
\hline 2002 & 11278.36 & 248.46 & 2884.60 & - \\
\hline 2003 & 10841.76 & 247.79 & 3612.67 & - \\
\hline 2004 & 9002.71 & 224.17 & 3286.14 & - \\
\hline 2005 & 7506.24 & 195.67 & 3160.82 & - \\
\hline 2006 & 6529.95 & 449.66 & 5691.74 & 13.98 \\
\hline 2007 & 5667.44 & 204.30 & 4286.80 & 11.91 \\
\hline 2008 & 4968.03 & 206.52 & 5140.90 & 18.51 \\
\hline 2009 & 4824.66 & 272.07 & 5948.39 & 50.10 \\
\hline 2010 & 4789.07 & 363.43 & 6514.73 & 27.20 \\
\hline 2011 & 4409.67 & 195.86 & 7002.29 & 29.71 \\
\hline 2012 & 3601.40 & 145.61 & 4683.00 & 60.08 \\
\hline 2013 & 2523.13 & 103.74 & 5034.74 & 77.42 \\
\hline 2014 & 2498.19 & 92.75 & 6540.74 & 84.55 \\
\hline
\end{tabular}

Note: - indicates the lack of data.

TABLE 7: Forecast results of the removal coefficients of pollutants in 2015 (unit: $t / 10^{8}$ Yuan).

\begin{tabular}{lccr}
\hline \multirow{2}{*}{ Forecast method } & \multicolumn{2}{c}{ The removal coefficients of pollutants } & $\mathrm{SO}_{2}$ \\
\hline LR & $\mathrm{COD}$ & Ammonia nitrogen & 6503.00 \\
GF & $-1206.00^{*}$ & 135.80 & $\times$ \\
ER & 1741.53 & $\times$ & 66.63 \\
PR & 2085.52 & 127.80 & 110.45 \\
QR & 3099.84 & 161.19 & 112.52 \\
CR & 4924.04 & 67.34 & 5659.68 \\
\end{tabular}

Note: $*$ indicates that the value does not conform to the reality and $\times$ indicates the corresponding method does not pass significant test.

where $u_{1}, u_{2}$, and $u_{3}$ present the minimum, average, and maximum of all the effective forecast results, respectively. The values of the parameters in triangular fuzzy variables of FCCGP model are shown in Table 8.

4.2. FCCGP Model. According to the 12th five-year plan of Shandong province, the annual average growth rate of GDP is $9 \%$, the industrial structure in 2015 is $7: 48: 45$, the annual average growth rate of fixed assets investment is set about $15 \%$, energy consumption intensity and carbon emission intensity should drop by $17 \%$ and $18 \%$ from 2010 , the emissions of COD, ammonia nitrogen, $\mathrm{SO}_{2}$, and $\mathrm{NO}_{X}$ should drop by $12 \%, 13.3 \%, 14.9 \%$, and $16.1 \%$, respectively. GDP, energy consumption intensity, carbon emission intensity, and the emissions of COD, ammonia nitrogen, $\mathrm{SO}_{2}$, and $\mathrm{NO}_{X}$ in 2010 are 2855.321 billion Yuan, 56.85 tce per million Yuan, 166.62 tons per million Yuan, 295127.6 t, $15441.3 \mathrm{t}, 1382874 \mathrm{t}$, and $1167190 \mathrm{t}$, respectively, so the targets of above indicators in 2015 are 4393.265 billion Yuan, 46.62 tce per million Yuan, 136.62 tons per million Yuan, 259712.3 t, 13387.6 t, $1176826 \mathrm{t}$, 
TABLE 8: The values of the parameters in triangular fuzzy variables of FCCGP model.

\begin{tabular}{lccc}
\hline Variable & $u_{1}$ & $u_{2}$ & $u_{3}$ \\
\hline$I_{1}$ & 19.74 & 20.60 & 21.21 \\
$I_{2}$ & 12.72 & 15.49 & 17.31 \\
$I_{3}$ & 6.38 & 7.78 & 8.37 \\
$P_{1}$ & 91.05 & 127.19 \\
$P_{2}$ & 57.94 & 4.56 & 5.84 \\
$P_{3}$ & 2.91 & 245.02 & 282.99 \\
$P_{4}$ & 225.62 & 54.05 & 70.03 \\
$c$ & 45.22 & 1.1433 & 1.3464 \\
$E_{1}$ & 0.9863 & 2962.73 & 4924.04 \\
$E_{2}$ & 1741.53 & 123.03 & 161.19 \\
$E_{3}$ & 67.34 & 6017.87 & 6655.57 \\
$E_{4}$ & 4731.15 & 99.78 & 113.16 \\
\hline
\end{tabular}

and $979272 \mathrm{t}$, respectively. Assuming the annual average growth rate of fixed assets investment fluctuates from $12 \%$ to $18 \%$, the lower and upper bounds of the fixed assets investment of three industries are 380.13 and 400.49 billion Yuan.

According to the requirements of new normal economy that emphasize structural adjustment, the elimination of energy bottleneck and green low-carbon development, and the effects that Shandong province has achieved at the early time, the GDP proportion of tertiary industry, energy consumption intensity, and $\mathrm{CO}_{2}$ emission intensity should be paid more attention in 2015. Assuming the predetermined confidence levels of all the targets are $\alpha_{1}=0.9, \alpha_{2}=0.9$, $\alpha_{3}=0.95, \alpha_{4}=0.9, \beta=0.95, \gamma_{1}=0.9, \gamma_{2}=0.9$, $\gamma_{3}=0.9, \gamma_{4}=0.9$, and $\gamma_{5}=0.95$, the priority orders of three subsystems are economy $>$ energy $>$ environment, and the weighting factors of deviations corresponding to economy subsystem and environment subsystem are all equal to 1 , and a FCCGP model can be constructed as follows:

$$
\begin{aligned}
& \min \left\{P_{1}\left(d_{1}^{+}+d_{2}^{+}+d_{3}^{-}+d_{4}^{-}\right), P_{2} d_{5}^{+},\right. \\
& \left.P_{3}\left(d_{6}^{+}+d_{7}^{+}+d_{8}^{+}+d_{9}^{+}+d_{10}^{+}\right)\right\}, \\
& G=\sum_{i=1}^{3}\left(I_{i} \times x_{i}\right), \\
& \operatorname{Cr}\left\{\frac{I_{1} \times x_{1}}{G}-0.07 \leq d_{1}^{+}\right\} \geq \alpha_{1}, \\
& \operatorname{Cr}\left\{\frac{I_{2} \times x_{2}}{G}-0.48 \leq d_{2}^{+}\right\} \geq \alpha_{2}, \\
& \operatorname{Cr}\left\{0.45-\frac{I_{3} \times x_{3}}{G} \leq d_{3}^{-}\right\} \geq \alpha_{3}, \\
& \operatorname{Cr}\left\{(43932.65-G) \times 10^{-5} \leq d_{4}^{-}\right\} \geq \alpha_{4}, \\
& \operatorname{Cr}\left\{\frac{x_{4}}{G}-0.4662 \leq d_{5}^{+}\right\} \geq \beta,
\end{aligned}
$$

$$
\begin{aligned}
& \operatorname{Cr}\left\{\left(P_{1} \times I_{2} \times x_{2}-E_{1} \times x_{5}-295127.6\right) \times 10^{-6}\right. \\
&\left.\leq d_{6}^{+}\right\} \geq \gamma_{1}, \\
& \operatorname{Cr}\left\{\left(P_{2} \times I_{2} \times x_{2}-E_{2} \times x_{5}-15441.3\right) \times 10^{-5} \leq d_{7}^{+}\right\} \\
& \geq \gamma_{2}, \\
& \operatorname{Cr}\left\{\left(P_{3} \times I_{2} \times x_{2}-E_{3} \times x_{5}-1382874\right) \times 10^{-7} \leq d_{8}^{+}\right\} \geq \gamma_{3}, \\
& \operatorname{Cr}\left\{\left(P_{4} \times I_{2} \times x_{2}-E_{4} \times x_{5}-1167190\right) \times 10^{-7} \leq d_{9}^{+}\right\} \\
& \quad \geq \gamma_{4}, \\
& \operatorname{Cr}\left\{\frac{c \times x_{4}}{G}-1.3662 \leq d_{10}^{+}\right\} \geq \gamma_{5}, \\
& \quad x_{i}^{-} \leq x_{i} \leq x_{i}^{+}, i=1,2, \ldots, 5, \\
& \quad 3801.3 \leq \sum_{i=1}^{3} x_{i} \leq 4004.9
\end{aligned}
$$

where the lower and upper bounds of all the decision variables are shown in Table 2, and the values of triangular distribution parameters of fuzzy variables are shown in Table 8.

4.3. Solution and Discussions. According to the above hybrid intelligent algorithm, the population size $m=50$, evaluation function parameter $a=0.05$, crossover probability $p_{j}=0.3$, mutation probability $p_{b}=0.2$, and generation cycles $T=$ 3000. Running the hybrid intelligent algorithm, the optimal solutions of 3Es system optimization model of Shandong province are shown in Table 9. The results of economic priority scenario show that economic subsystem achieves its targets, but energy and environment subsystems do not achieve their targets. The unachieved indicators include the following: the energy consumption intensity is 54.49 tce per million Yuan, the emissions of $\mathrm{SO}_{2}$ and $\mathrm{NO}_{X}$ are $1566900 \mathrm{t}$ and $979302 \mathrm{t}$, and $\mathrm{CO}_{2}$ emission intensity is 139.22 tons per million Yuan.

In economic priority scenario, there are greater differences between the optimized results and the targets in energy and environment subsystems. Considering the importance of environment subsystem for sustainable development, environment priority scenario is defined with the priority orders of three subsystems that are environment $>$ economy $>$ energy. Running the hybrid intelligent algorithm, the optimal solutions are shown in Table 10. The results show that environment and energy subsystem achieve their targets, but economic subsystem does not achieve its target. The unachieved indicators include the following: the optimized GDP is 4332.194 billion Yuan, and the industrial structure is $8: 50: 42$. 
TABLE 9: Solution results of FCCGP model of Shandong province in economic priority scenario.

\begin{tabular}{lc}
\hline Variable & Solution \\
\hline$x_{1}^{*}$ & 130.7 \\
$x_{2}^{*}$ & 1784.5 \\
$x_{3}^{*}$ & 2008 \\
$x_{4}^{*}$ & 37470.8 \\
$x_{5}^{*}$ & 879.9 \\
$d_{1}^{+}$ & 0 \\
$d_{2}^{+}$ & 0 \\
$d_{3}^{-}$ & 0 \\
$d_{4}^{-}$ & 0 \\
$d_{5}^{+}$ & 0.0787 \\
$d_{6}^{+}$ & 0 \\
$d_{7}^{+}$ & 0 \\
$d_{8}^{+}$ & 390074.21 \\
$d_{9}^{+}$ & 29.57 \\
$d_{10}^{+}$ & 0.0262 \\
\hline
\end{tabular}

TABLE 10: Solution results of FCCGP model of Shandong province in environment priority scenario.

\begin{tabular}{lc}
\hline Variable & Solution \\
\hline$x_{1}^{*}$ & 130.7 \\
$x_{2}^{*}$ & 1716.2 \\
$x_{3}^{*}$ & 2008 \\
$x_{4}^{*}$ & 37080.1 \\
$x_{5}^{*}$ & 1307.6 \\
$d_{1}^{+}$ & 0.0101 \\
$d_{2}^{+}$ & 0.0204 \\
$d_{3}^{-}$ & 0.0103 \\
$d_{4}^{-}$ & 610.71 \\
$d_{5}^{+}$ & 0 \\
$d_{6}^{+}$ & 0 \\
$d_{7}^{+}$ & 0 \\
$d_{8}^{+}$ & 0 \\
$d_{9}^{+}$ & 0 \\
$d_{10}^{+}$ & 0 \\
\hline
\end{tabular}

A scenario endowing the equivalent status for three subsystems is put forward to compare with the first two scenarios. The optimal solutions are shown in Table 11. The results show that all three subsystems do not achieve their targets. The unachieved indicators include the following: the optimized GDP is 4338.292 billion Yuan, the industrial structure is $8: 50: 42$, the energy consumption intensity is 56.12 tce per million Yuan, and the emissions of $\mathrm{SO}_{2}$ are $1340146 \mathrm{t}$.

It can be known from the comparison of three scenarios that the results of the scenario of equivalent status are not improved better than those of environment priority scenario, while environment priority scenario is better than economic priority scenario. Therefore, the optimization results of environment priority scenario can be applied to guide practice
TABLE 11: Solution results of FCCGP model of Shandong province in the scenario of equivalent status.

\begin{tabular}{lc}
\hline Variable & Solution \\
\hline$x_{1}^{*}$ & 130.7 \\
$x_{2}^{*}$ & 1749.6 \\
$x_{3}^{*}$ & 2008 \\
$x_{4}^{*}$ & 44278.8 \\
$x_{5}^{*}$ & 1103.5 \\
$d_{1}^{+}$ & 0.0007 \\
$d_{2}^{+}$ & 0.0186 \\
$d_{3}^{-}$ & 0.0293 \\
$d_{4}^{-}$ & 549.72 \\
$d_{5}^{+}$ & 0.0949 \\
$d_{6}^{+}$ & 0 \\
$d_{7}^{+}$ & 0 \\
$d_{8}^{+}$ & 163320 \\
$d_{9}^{+}$ & 0 \\
$d_{10}^{+}$ & 0 \\
\hline
\end{tabular}

of 3Es system optimization of Shandong province. In 2015, $13.07,171.62$, and 200.8 ten billion Yuan can be invested into the primary, secondary, and tertiary industries, respectively, total energy consumption should be controlled below 370.801 million tce, and 130.76 ten billion Yuan can be invested into environmental pollution control.

The optimization results show that Shandong province should increase the investments in fixed assets of three industries and environmental pollution control in 2015. The investments in fixed assets of the primary, secondary, and tertiary industries in 2015 can be 17\%, 4.73\%, and 7.59\% higher than those in 2014, respectively. The total investments in fixed assets and environmental pollution control in 2015 can be $6.55 \%$ and $6.81 \%$ higher than those in 2014. Meanwhile, the total energy consumption in 2015 can be merely $2.63 \%$ more than that in 2014, which means the growth should be slowed. Practically, Shandong province is undergoing a critical period of structural adjustment at present. The secondary industry consumes considerable amount of energy and causes environmental pollutions and carbon emissions; therefore, it is reasonable to reduce the investment growth of the secondary industry. On the contrary, increasing the investment in the tertiary industry and speeding up its development can reduce energy consumption and environmental pollutions. In addition, the carrying capacity of energy resources in Shandong province has been continuously improving, so it is necessary to reduce the growth of energy consumption while ensuring economic development, which means that Shandong province should strengthen energy conservation, improve energy efficiency, and develop alternative energy sources.

\section{Conclusions}

In this study, we have analyzed the structure of 3 Es system and selected the typical indicators to demonstrate the main causal relationships. The target parameters and decision variables 
are set and a FCCGP model is put forward for 3Es system optimization. In the FCCGP model, uncertain parameters are fuzzy variables, and fuzzy chance constraints are satisfied with certain confidence levels. The proposed model is essentially flexible, and any number and form of fuzzy goals and constraints can be contained into it. A hybrid intelligent algorithm including fuzzy simulation and genetic algorithm is put forward for solving the uncertain model. Depending upon the nature of the study region, the user can modify the model and algorithm inputs to get desired outputs. After the empirical analysis on Shandong province, we can conclude that the parameters of 3Es system optimization can be regarded as triangular fuzzy numbers, and FCCGP models with fuzzy variables can demonstrate the relations of interaction among three subsystems. The results of 3Es system optimization of Shandong province testify the feasibility of FCCGP models, which can be applied to guide the practice of 3Es system optimization so as to realize their harmonious development. According to the optimization results, Shandong province should obey the rule of environment priority. In this scenario, 3Es system can realize relatively more scientific development, although it may lower the economic development to a certain extent.

Limited by the definition of research object and availability of data, in this paper, we neither include imports and exports, household consumption and other contents into economic subsystem, nor take into consideration land, forest, mineral, water resources, population, science and technology, and other subsystems. This weakened the complex relationship between each subsystem in some certain extent and might affect the objectivity of the programming results, which should be improved in the future studies.

\section{Competing Interests}

The authors declare that there is no conflict of interests regarding the publication of this paper.

\section{Acknowledgments}

This work is supported by Natural Science Foundation of Shandong Province (ZR2015GM008), MOE (Ministry of Education in China) Project of Humanities and Social Sciences (16YJAZH054), and the Fundamental Research Funds for the Central Universities (15CX04101B).

\section{References}

[1] Y. Wei, G. Wu, L. Liu et al., "Progress in modeling for energyeconomy-environment complex system and its applications," Chinese Journal of Management, vol. 2, no. 2, pp. 159-170, 2005.

[2] J.-M. Burniaux, J. P. Martin, G. Nicoletti, and J. O. Martins, "GREEN a multi-sector, multi-region general equilibrium model for quantifying the costs of curbing $\mathrm{CO}_{2}$ emissions: a technical manual," Tech. Rep., OECD Publishing, Paris, France, 1992.

[3] W. J. Mckibbin and P. J. Wilcoxen, "The theoretical and empirical structure of the G-Cubed model," Economic Modelling, vol. 16, no. 1, pp. 123-148, 1998.
[4] J.-M. Burniaux and J. O. Martins, "Carbon leakages: a general equilibrium view," Economic Theory, vol. 49, no. 2, pp. 473-495, 2012.

[5] A. Zhang and J. Li, "Review of hybrid approaches of energyeconomy-environmental system model," Journal of Systems Engineering, no. 2, pp. 170-175, 2007.

[6] C. Zhang, J. Li, A. Zhang, and C. Bi, "SICGE extensions and their linkage with IESOM," Journal of Tsinghua University, vol. 51, no. 2, pp. 234-240, 2011.

[7] J. F. DeCarolis, S. Babaee, B. Li, and S. Kanungo, "Modelling to generate alternatives with an energy system optimization model," Environmental Modelling \& Software, vol. 79, pp. 300310, 2016.

[8] N. S. Kambo, B. R. Handa, and R. K. Bose, "A linear goal programming model for urban energy-economy-environment interaction," Energy and Buildings, vol. 16, no. 1-2, pp. 537-551, 1991.

[9] C. Oliveira and C. H. Antunes, "A multiple objective model to deal with economy-energy-environment interactions," European Journal of Operational Research, vol.153, no. 2, pp. 370-385, 2004.

[10] Y.-M. Wei, R. Zeng, Y. Fan, H. Tsai, W.-X. Xu, and X.-F. Fu, "Multi-objective goal programming model for Beijing's coordination development of population, resources, environment and economy," System Engineering Theory \& Practice, vol. 22, no. 2, pp. 74-83, 2002.

[11] Z. Hu, J. Yuan, and Z. Hu, "Study on China's low carbon development in an economy-energy-electricity-environment framework," Energy Policy, vol. 39, no. 5, pp. 2596-2605, 2011.

[12] L. Liu, G. H. Huang, G. A. Fuller, A. Chakma, and H. C. Guo, "A dynamic optimization approach for nonrenewable energy resources management under uncertainty," Journal of Petroleum Science and Engineering, vol. 26, no. 1-4, pp. 301-309, 2000.

[13] Y. P. Cai, G. H. Huang, Q. G. Lin, X. H. Nie, and Q. Tan, "An optimization-model-based interactive decision support system for regional energy management systems planning under uncertainty," Expert Systems with Applications, vol. 36, no. 2, pp. 3470-3482, 2009.

[14] E. Fragnière and A. Haurie, "A stochastic programming model for energy/environment choices under uncertainty," International Journal of Environment and Pollution, vol. 6, no. 4-6, pp. 587-603, 1996.

[15] Q. G. Lin and G. H. Huang, "An inexact two-stage stochastic energy systems planning model for managing greenhouse gas emission at a municipal level," Energy, vol. 35, no. 5, pp. 22702280, 2010.

[16] A. R. Borges and C. H. Antunes, "A fuzzy multiple objective decision support model for energy-economy planning," European Journal of Operational Research, vol. 145, no. 2, pp. 304316, 2003.

[17] K. Weber and D. Martinsen, "From system cost minimization to sustainability maximization - a new fuzzy program approach to energy systems analysis," Fuzzy Sets and Systems, vol. 231, pp. 1$25,2013$.

[18] L. Zhang, D.-Q. Zhou, P. Zhou, and Q.-T. Chen, "Modelling policy decision of sustainable energy strategies for Nanjing city: a fuzzy integral approach," Renewable Energy, vol. 62, pp. 197203, 2014.

[19] B. Liu, R. Zhao, and G. Wang, Uncertain Programming and Applications, Tsinghua University Press, Beijing, China, 2003. 
[20] J. Song and Y. Zhang, "Random fuzzy programming models and hybrid intelligent algorithm for oilfield exploitation plan," International Journal of Advancements in Computing Technology, vol. 4, no. 6, pp. 118-125, 2012.

[21] Q. Wang, X. Yuan, X. Cheng, R. Mu, and J. Zuo, "Coordinated development of energy, economy and environment subsystems-a case study," Ecological Indicators, vol. 46, pp. 514-523, 2014.

[22] W. Ke and W. Yiming, "China's regional energy efficiency index analysis and forecasting," Bulletin of Chinese Academy of Sciences, vol. 27, no. 4, pp. 493-501, 2012. 

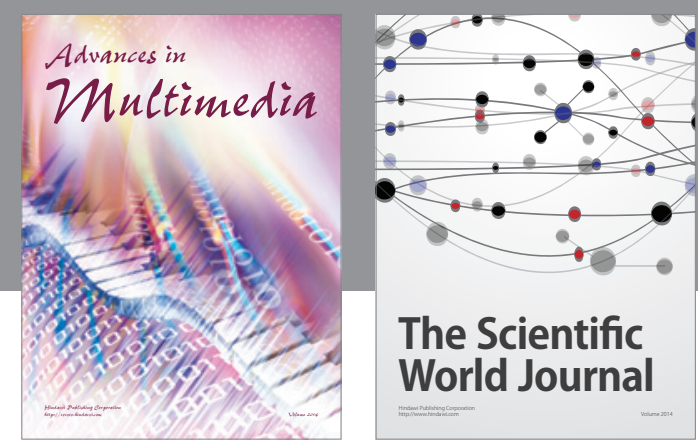

The Scientific World Journal
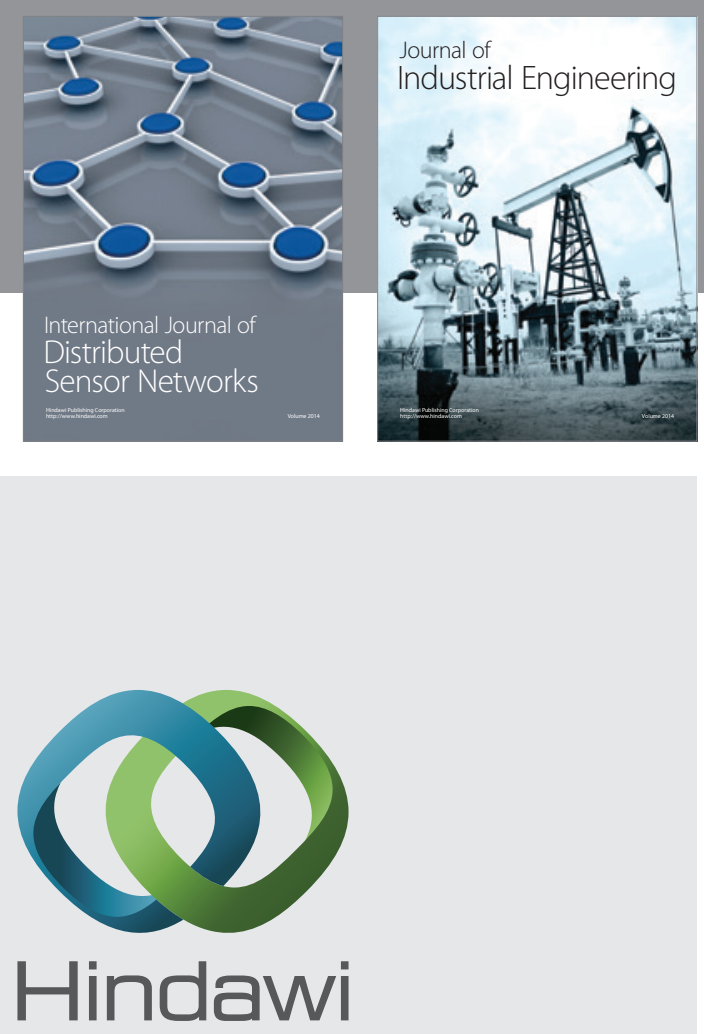

Submit your manuscripts at

http://www.hindawi.com

\section{Computer Networks} and Communications
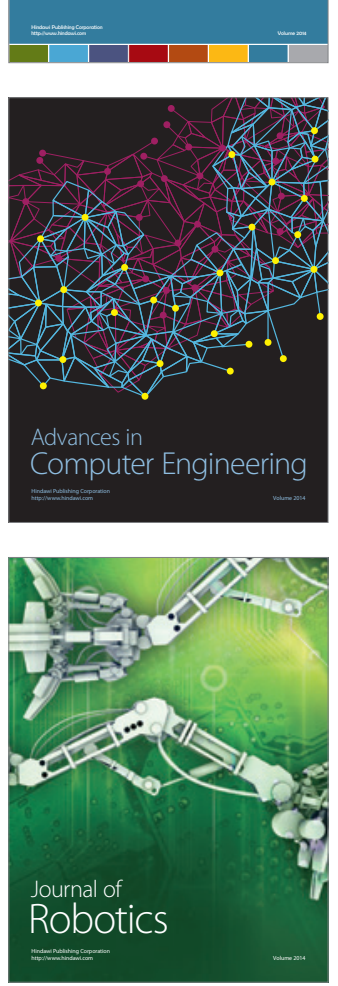
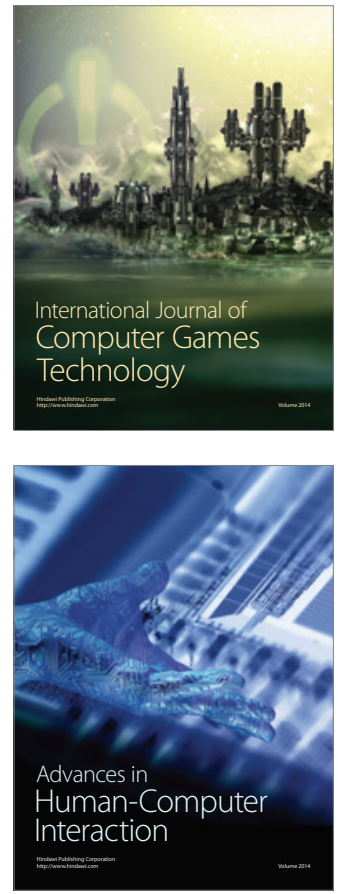
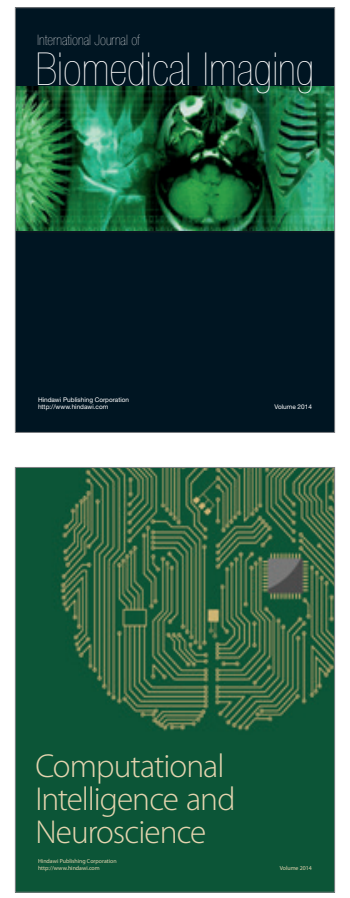
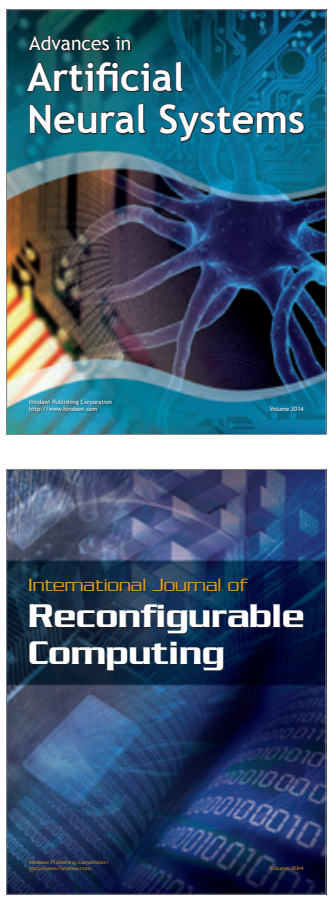
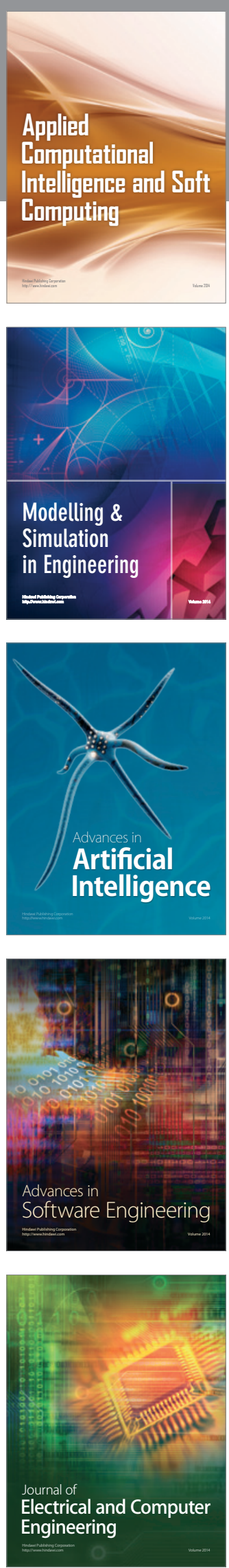